\title{
Los servicios digitales de seguimiento de noticias bajo la mirada del derecho de autor*
}

\author{
Digital services
the copyright.
}

\section{Patricia Reyes Olmedo**}

\section{RESUMEN}

El artículo describe y analiza los modernos servicios digitales de seguimiento de noticias y artículos periodisticos que son demandados bajo contrato por las empresas, y que implican la búsqueda, recuperación selección, empaquetamiento y distribución de esos artículos, que en si mismos constituyen obras del intelecto humano y por tanto son objeto de protección por el derecho de autor.

El artículo revisa las figuras y estándares de protección de la propiedad intelectual para el resultado de esta actividad en el ámbito internacional y posteriormente examina su aplicación bajo la ley de propiedad intelectual chilena.

\section{PALABRAS CLAVE}

Propiedad intelectual, derecho de autor, servicio de seguimiento de noticias, Convenio de Berna, revistas de prensa, dossier de prensa.

\begin{abstract}
The article describes and analyzes follow-up services of modern news digital services and journalistic articles that are claim under contract by the companies, and which involve the search, recovery, selection, packaging and distribution of these articles, which in themselves constitute human intellectual work and therefore it is protected by copyright law.

The paper describes and analyzes the digital services for tracking news that are demanded under contract by the companies. This services involve the search, recovery, selection, packaging and distribution of news, which in themselves constitute intellect work and are protected by copyright. The article reviews the international standards of protection and examine it under by Chilean intellectual property law.
\end{abstract}

\section{KEYWORDS}

Intellectual property, copyright, news follow-up service, Berne Convention, press magazines, press dossier

*Artículo recibido el 30 de junio de 2017 y aceptado el 23 de agosto de 2017

**Universidad de Valparaiso, Chile. (patricia.reyes@uv.cl) orcid 0000-0003-2841-6596 
SUMARIO

1. Los servicios de seguimiento de noticias

2. Estándares comparados de protección

3. La protección en Chile

4. Conclusiones

\section{Los servicios de seguimiento de noticias}

La sociedad red, basada en la interconexión e intercambio permanente entre los nodos que componen su estructura, exige inmediatez y actualización continua a los individuos que interactúan en la red, sean estos personas individuales o empresas. Si hablamos de hechos noticiosos, la necesidad es perentoria y la inmediatez requiere prácticamente ser instantánea. Sin embargo, realizar un seguimiento permanente de las publicaciones de los principales medios de comunicación, que decir de todos, resulta prácticamente imposible o exige una ingente cantidad de recursos e infraestructura.

Esta situación ha determinado que los servicios de seguimiento y monitoreo de noticias, existentes desde hace más de un siglo, se incrementaran en los últimos años. Sus soportes y formatos han mutado al ambiente digital en atención a su permanente adaptación a un cliente con necesidades también cambiantes. Hoy en día actúa principalmente en este espacio.

Diferentes autores han definido estos servicios. Así, podemos encontrar conceptualizaciones como la de Carbajo:

Consisten en la vigilancia o el seguimiento de informaciones publicadas en prensa $u$ otros medios de comunicación audiovisual o digital, sea sobre noticias de actualidad general o sobre materias, personas o instituciones concretas, para luego presentarlas de manera extractada, resumida o íntegra (según los casos) en forma de dossier o panorama informativo que se envía periódicamente a un cliente. ${ }^{1}$

\footnotetext{
' Carbajo, Fernando, "El concepto de autor en el pseudolimite de recortes de prensa (Press Clipping)", Sentencia de la
} Audiencia Provincial de Madrid, sección 28a, 2 de diciembre del 2011, en V. Jurisprudencia y Resoluciones, p. 698. 
Para Caparrós de Olmedo, ${ }^{2}$ el seguimiento de medios de prensa a partir del cual se elabora una serie de dosieres de noticias, resumidas o completas, habitualmente a solicitud del usuario o cliente, en conjunto con los programas computacionales que establecen sistemas de búsqueda, selección y organización de la información, hacen surgir este servicio en su carácter digital.

Córdova señala:

Consiste en el seguimiento y selección de noticias brindadas por los medios de comunicación para remitirlas en formada organizada a las personas naturales o instituciones que les requieren de acuerdo a sus intereses. Así, quienes brindan este servicio, monitorean las noticias aparecidas principalmente en la web, las copian y las ordenan de acuerdo con criterios de selección preestablecidos para remitirlas periódicamente a sus usuarios. ${ }^{3}$

Tobón ${ }^{4}$ define el producto o la prestación como "compilaciones de recortes de noticias que han sido elaboradas y publicadas por otros a través de diversas técnicas como el redireccionamiento, los links y el framing".

Por nuestra parte, podemos señalar que el servicio de seguimiento o monitoreo de noticias es una actividad que consiste en la búsqueda, captura, procesamiento y recopilación de artículos de prensa o revistas por una empresa proveedora, para su entrega a un cliente contratante del servicio. En esta prestación de servicios, los artículos son normalmente seleccionados por la empresa proveedora con base en intereses previamente definidos por o con el usuario. Son compilados en un soporte digital, y en el formato elegido también por el usuario.

De este modo, como resultado de esta actividad, puede enviarse al cliente, vía telemática, un conjunto de artículos periodísticos ${ }^{5}$ en formato de textos completos, fragmentos, resúmenes, enlaces o hipervínculos, o incluso poner

\footnotetext{
${ }^{2}$ Caparrós de Olmedo, Silvia, "El derecho de Cita y el Press Clipping", en Nuria Ginés Cantellet (coord.), Novedades en la Ley de Propiedad Intelectual, Barcelona, Bosch, 2007, p. 89.

${ }^{3}$ Córdova, JoRGE, "El press clipping y el uso de enlances desde la perspectiva del derecho de autor", Revista de Derecho PUCP, núm. 74, 174.

${ }^{4}$ Toвón, Natali, Legalidad del "Press Clipping", Revista Foro Derecho Mercantil, núm. 47, p. 63.

${ }^{5}$ Según Ribera, se entiende por tal "un escrito que recoge la opinión de un autor sobre un tema, tratado de manera subjetiva y con un lenguaje más o menos culto que se inserta en una publicación de aparición regular (diaria, semanal, quincenal, etc.), cuya base es la difusión de información estructurada en distintas secciones. Si la publicación es de difusión diaria se suele denominar diario o periódico; si la periodicidad es superior a un dia, se utiliza frecuentemente el término revista y ésta a su vez puede ser semanal, quincenal, mensual, e incluso, bimensual". RiBERA, BEgoña, "Recopilaciones periódicas, reseñas, revistas de prensa y press clipping", en Juan Antonio Moreno Martínez (coord.), Limites a la propiedad intelectual y nuevas tecnologías, Madrid, Dickynson, 2009, p. 22.
} 
a su disposición una base de datos. En todos los casos, irían acompañados de información o metadatos ${ }^{6}$ que identifican a cada artículo.

De acuerdo con Cordova ${ }^{7}$ y Ortega $^{8}{ }^{8}$ los hipervínculos ${ }^{9}$ pueden ser del siguiente tipo:

- Enlaces superficiales (surfaces links). Son aquellos que llevan directamente a una página web inicial de otro sitio web.

- Enlaces profundos (deep links). Son aquellos que dirigen a una sección específica de una página web.

- Enlaces ensamblados (embedded links). Son aquellos enlaces que integran un fragmento de una página web a otra sin que el usuario sea consciente de este hecho, pues no se percibe la existencia de un vínculo y no existe la necesidad de ser redireccionado a otra página web.

- Enlaces marco (frames). Son aquellos que permiten visualizar el contenido de la página web de un tercero enmarcada dentro de la página web que contiene el enlace. Normalmente aparece como una ventana $o$ banner dedicado.

Desde un punto de vista jurídico, se debe establecer previamente que la información noticiosa "es libre y no aprehensible por nadie, y por tanto, carece de la protección que otorga el derecho de autor; de manera que no se requiere la aplicación de ninguna excepción para su reproducción”. ${ }^{10}$ Así se reconoce en el numeral 8 del artículo 2 del Convenio de Berna: "La protección del presente Convenio no se aplicará a las noticias del día ni de los sucesos que tengan el carácter de simples informaciones de prensa”.

La Guía del Convenio de Berna explica esta disposición de la siguiente manera:

\footnotetext{
${ }^{6}$ Los metadatos son información sobre los datos, generalmente no contenida expresamente en el documento noticioso, como puede ser, por ejemplo, el editor, el autor, la fecha, página, los temas a los que refiere, entre otros.

${ }^{7}$ Córdova, Jorge, "El press clipping y el uso de enlances desde la perspectiva del derecho de autor", Revista de Derecho PUCP, núm. 74, p. 179.

${ }^{8}$ Ortega, Juan Francisco, "Linking y derechos de autor: otro reto para equilibrio entre derechos exclusivos y excepciones. Una visión desde el derecho español", Revista de Derecho, comunicaciones y nuevas tecnologías, núm. 5, pp. 6-8.

9 Iglesias los define como "un conjunto de instrucciones que hace posible que un programa informático pueda acceder correctamente a un determinado recurso de millones existentes en la red, ya sean documentos de hipertexto, imágenes, videos o archivos de cualquier tipo". IGLESIAS, RUBÉN, "Provisión de enlaces electrónicos a contenidos protegidos por el derecho de autor", Actas de Derecho industrial y Derecho de Autor, núm. 32, p. 148.

${ }^{10}$ Caparrós de Olmedo, Silvia, "El derecho de Cita y el Press Clipping", en Nuria Ginés Cantellet (coord.), Novedades en la Ley de Propiedad Intelectual, Barcelona, Bosch, 2007, p. 99.
} 
Esta disposición significa que el convenio excluye de la protección las simples informaciones acerca de las noticias del día o de los sucesos, ya que semejante material no posee las características requeridas para constituir una obra.

En cambio, los artículos escritos por periodistas, así como cualquier otra obra "periodística" en las que se den o comenten noticias, gozarán de protección en la medida en que lleven inherente una aportación intelectual que permita considerarlas como obras literarias o artísticas.

En consecuencia, cuando la información noticiosa se expresa de una manera original, estamos ante una obra protegida por derechos de autor. Así ocurre con una crónica o un artículo periodístico, ${ }^{11}$ respecto de la cual concurren como titulares de derechos morales y derechos patrimoniales sus autores o editores.

De aquí entonces el debate jurídico que tiene lugar respecto a la protección que cabe sobre el resultado entregado al cliente a partir de la actividad de seguimiento y monitoreo de artículos periodísticos.

En el ámbito específico, se discute si estos productos, que como vemos son obras intelectuales en sentido estricto, vulneran los derechos de propiedad intelectual. Si bien ellos, la mayoría de las veces, reconocen la paternidad al autor del texto original, en general sus prestadores no realizan ningún pago económico por la reproducción de la obra. Para algunos autores, se trata de un modelo de negocios en que terceros (normalmente empresas) lucran indebidamente del esfuerzo de otros, pues quienes prestan el servicio no han participado en modo alguno durante el proceso de creación o edición del artículo distribuido.

Para otros autores en cambio, se trata de un producto que no viola el derecho de autor, toda vez que, o puede ser reconocido dentro del derecho de cita, o es posible considerar que el resultado de esta actividad constituye una obra en sí misma. Puede ser el caso de una compilación o base de datos, por tanto, distinta de las obras periodísticas compiladas, enlazadas o recogidas en bases de datos y entregadas al cliente.

Para analizar la materia a la luz de la protección o no dentro de la legis173 lación chilena, revisaremos los estándares internacionales de protección al resultado de esta actividad, para luego contrastarlas con la legislación nacional.

\footnotetext{
11 "Un escrito que recoge la opinión de un autor sobre un tema, tratado de manera subjetiva y con un lenguaje más o menos culto que se inserta en una publicación de aparición regular [...] que independiente de su periocidad, tenga una difusión generalizada de la sociedad porque incorpore elementos de actualidad que tengan un interés general". Puede incluirse: "a) una noticia o información elaborada y firmada por un periodista; b) una entrevista; c) un reportaje sobre un tema concreto".
} 


\section{Estándares comparados de protección}

La normativa contenida en el Convenio de Berna para la protección de obras literarias y artísticas de 1886 constituye el principal instrumento internacional de regulación del derecho autoral.

En este convenio se reconoce en el derecho de cita, como excepción a la exclusiva del derecho de autor. Es la base legal en la que se ha sustentado la actividad de seguimiento de medios y elaboración de resúmenes de prensa. Esta excepción encuentra su primer reconocimiento en el Convenio de Berna. Para la protección de las obras literarias y artísticas, en su artículo 10 dispone: "Son lícitas las citas tomadas de una obra que se haya hecho lícitamente accesible al público, a condición de que se hagan conforme a los usos honrados y en la medida justificada por el fin que se persiga, comprendiéndose las citas de artículos periodísticos y colecciones periódicas bajo la forma de revistas de prensa”.

Otra fuente legal en el ámbito internacional lo constituye el artículo 2.5 del mismo convenio, el cual reconoce como obras protegidas las compilaciones: "Las colecciones de obras literarias y artísticas tales como las enciclopedias y antologías que, por la selección o la disposición de las materias, constituyan creaciones intelectuales, estarán protegidas como tales, sin perjuicio de los derechos de los autores sobre cada uno de las obras que forman parte de esas colecciones".

En el ámbito del derecho extranjero y comparado, no ha sido del todo pacífico el debate jurídico para determinar si el resultado de la actividad de seguimiento y monitoreo de noticias es una obra que vulnera o no los derechos de autor.

En Europa, esta cuestión no está claramente resuelta en la Directiva 2001/29/CE, de 22 de mayo de 2001, relativa a la armonización de determinados aspectos de los derechos de autor y derechos afines en la sociedad de la información. Por lo tanto, se deja a los Estados miembro adoptar sus propias soluciones. Esto ha generado diferentes regulaciones en los países que con-

174 forman la Unión Europea. En efecto, el artículo 5.3 establece en las letras c) y d) limitaciones o excepciones a los derechos de autor que pudieran aplicarse indistintamente a los dosieres de prensa, y en el caso del 5.3 b) por vía de la excepción del derecho de cita. El texto de ambas disposiciones es el siguiente:

c) cuando la prensa reproduzca o se quiera comunicar o poner a disposición del público artículos publicados sobre temas de actualidad económica, política o religiosa, o emisiones de obras o prestaciones del mismo carácter, en los casos en que dicho uso no esté reservado de 
manera expresa, y siempre que se indique la fuente, incluido el nombre del autor, o bien cuando el uso de obras o prestaciones guarde conexión con la información sobre acontecimientos de actualidad, en la medida en que esté justificado por la finalidad informativa y siempre que, salvo en los casos en que resulte imposible, se indique la fuente, con inclusión del nombre del autor.

d) cuando se trate de citas con fines de crítica o reseña, siempre y cuando éstas se refieran a una obra o prestación que se haya puesto ya legalmente a disposición del público, se indique, salvo en los casos en que resulte imposible, la fuente, con inclusión del nombre del autor, y se haga buen uso de ellas, y en la medida en que lo exija el objetivo específico perseguido.

Entre las soluciones adoptadas por los países europeos, ha estado la de incorporar expresamente, en sus legislaciones de propiedad intelectual, una excepción o limitación a la propiedad intelectual de carácter particular para hacer referencia a las recopilaciones periódicas de recortes de prensa o la de incorporarlas dentro de la excepción del derecho de cita.

A continuación, se presenta la regulación que sobre esta materia adoptan algunos países. Nos parecen relevantes para la comparación posterior con el marco normativo chileno, y para futuras regulaciones sobre la materia.

En Francia, el Code de la Propriété Intelectuelle, en su artículo L. 122-5-3º b), prescribe expresamente una limitación al derecho patrimonial de los autores, no así por supuesto el derecho moral: "cuando la obra ha sido divulgada, el autor no puede prohibir 'les revues de presse', siempre que se indique claramente el nombre del autor y la fuente".

En Italia, si bien no hay una referencia expresa a las recopilaciones o dosieres de prensa como citas, se ha entendido que se encuentra dentro de las limitaciones comprendidas dentro de la Legge de 1941 (modificada en 2003). En su artículo 70 reconoce la excepción de cita, para fines de crítica, discusión, enseñanza o investigación, dentro de los límites justificados por dichos fines y siempre que no constituya competencia con la utilización económica de la obra.

Por otro lado, en Portugal, el artículo 75.2 letra c) del Código do Direito de Autor e dos Direitos Conexos dispone que "es lícita, sin consentimiento del autor, la utilización de la obra consistente en la selección regular de artículos de prensa periódica, bajo la forma de revista de prensa". 
En Alemania se reconoce amparado por la limitación de cita. Por tanto, se encuentran eximidos de las contraprestaciones pecuniarias exigidas por la ley para otras obras. El 49 de la URHG contempla en su apartado 1: "En el caso de reproducción, puesta en circulación y comunicación pública hay que pagar una remuneración equitativa, salvo en caso de reproducción, puesta en circulación o comunicación pública de breves pasajes extraídos de varios comentarios o artículos bajo la forma de revista de prensa".

En materia de jurisprudencia, se ha entendido además por la jurisprudencia que dentro de las revistas de prensa, mencionadas en la ley, se encuentran comprendidos los dosieres electrónicos de prensa.

Para España, el texto refundido de la Ley de Propiedad Intelectual (TRLPI), contenida en el Real Decreto Legislativo 1/1996 del 12 de abril, establece un régimen especial. Distingue de manera poco precisa las revistas de prensa y con fines comerciales. Para este efecto, su artículo 32.1 párrafo 2 consigna:

Las recopilaciones periódicas efectuadas en forma de reseñas o revista de prensa tendrán la consideración de citas. No obstante, cuando se realicen recopilaciones de artículos periodísticos que consistan básicamente en su mera reproducción y dicha actividad se realice con fines comerciales, el autor que no se haya opuesto expresamente tendrá derecho a percibir una remuneración equitativa. En caso de oposición expresa del autor, dicha actividad no se entenderá amparada por este límite.

Por su parte, el artículo 32.2 dispone:

La puesta a disposición del público por parte de prestadores de servicios electrónicos de agregación de contenidos de fragmentos no significativos de contenidos, divulgados en publicaciones periódicas o en sitios Web de actualización periódica y que tengan una finalidad informativa, de creación de opinión pública o de entretenimiento, no requerirá autorización, sin perjuicio del derecho del editor o, en su caso, de otros titulares de derechos a percibir una compensación equitativa. Este derecho será irrenunciable y se hará efectivo a través de las entidades de gestión de los derechos de propiedad intelectual. En cualquier caso, la puesta a disposición del público por terceros de cualquier imagen, obra fotográfica o mera fotografía divulgada en publicaciones periódicas o en sitios Web de actualización periódica estará sujeta a autorización. 
Sin perjuicio de lo establecido en el párrafo anterior, la puesta a disposición del público por parte de prestadores de servicios que faciliten instrumentos de búsqueda de palabras aisladas incluidas en los contenidos referidos en el párrafo anterior no estará sujeta a autorización ni compensación equitativa siempre que tal puesta a disposición del público se produzca sin finalidad comercial propia y se realice estrictamente circunscrita a lo imprescindible para ofrecer resultados de búsqueda en respuesta a consultas previamente formuladas por un usuario al buscador y siempre que la puesta a disposición del público incluya un enlace a la página de origen de los contenidos.

Según lo que señala Marín, ${ }^{12}$ las modificaciones a este artículo han sido resultado de complejos debates parlamentarios influenciados por diferentes actores del mercado, provenientes tanto de las agrupaciones de editores de la prensa española, como de las empresas que prestan los servicios. Desafortunadamente, los grandes ausentes han sido los usuarios de los servicios.

De este modo, y como señala el propio Marín, vemos que para el derecho español "las reseñas y revistas de prensa se consideran una actividad cubierta por el derecho de cita". ${ }^{13}$ Por otro lado, y concurriendo determinados requisitos, la recopilación de artículos no se encuentra protegida por la limitación del derecho de cita. Tales requisitos son: $a$ ) que se trate de una recopilación de artículos periodísticos; $b$ ) que se haga mera reproducción total o parcial de ellos; c) que se haga con fines comerciales; $y d$ ) que no exista autorización expresa del autor. Estos elementos configuran la actividad de seguimiento y monitoreo de prensa en casi todos los casos en que no es gratuito, que son la mayoría.

La doctrina española ha entendido que precisamente fue esta actividad la que se quiso eximir, no de manera completamente adecuada, bajo la figura del artículo 32.1 párrafo 2 .

En definitiva, se puede señalar que, de acuerdo con este artículo, las recopilaciones de artículos periodísticos pueden presentarse como: a) recopilaciones periódicas, es decir, con un grado de frecuencia en el tiempo y sin fines comerciales, en cuyo caso se acogen al régimen excepcional de cita; y b) recopilaciones de artículos que consistan en su mera reproducción y con fines comerciales, las cuales deben pagar una remuneración equitativa al titular.

\footnotetext{
${ }^{12}$ Marin López, Juan José, "Derecho de autor, revistas de prensa y Press Clipping", Revue Internationale du Droit D'Auteur, vol. 215.

${ }^{13}$ Marin López, JuAn José, "Derecho de autor, revistas de prensa y Press Clipping", Revue Internationale du Droit D'Auteur, vol. 215, p. 11.
} 
Si esta situación ya era compleja de interpretar, a juicio de la doctrina española, el artículo 32.2, agregado en 2014, vino a confundir completamente la regulación. Incluyó los demás formatos en los que se puede entregar el producto de la actividad de seguimiento y monitoreo de prensa. En este último caso, es irrelevante que el resultado de la actividad sea una creación protegida por derechos de autor para acogerse a la excepción de cita. Lo anterior dado que establece un régimen diferenciado, en el cual ante la existencia de fines comerciales, limitados a una reproducción íntegra del artículo periodístico, necesariamente quien realice la recopilación debe pagar una remuneración al titular de los derechos sobre ésta.

En general, la doctrina española se ha manifestado contraria a la regulación que hace el TrLPI de esta actividad. Así, por ejemplo, Ribera ha señalado que:

No puede negarse el impacto provocado por el desarrollo de la labor de estas empresas en los últimos tiempos [...] estas empresas representan un modelo de negocio de imprescindible existencia en nuestra sociedad actual que se nutre de la utilización con ánimo de lucro de las obras intelectual creadas por terceras personas. Sin embargo, una vez más en la historia de la propiedad intelectual el cambio legislativo no se produce para tratar de otorgar mayor protección a los autores de los escritos, sino por motivos económicos, ante la pérdida de ganancias sufridas por las empresas editoras de periódicos y revistas. ${ }^{14}$

En el mismo sentido, Peinado y Solana indican:

[La] reiterada práctica de reproducción de los titulares, noticias y fotografías extraídas de los diarios con el fin de desarrollar su modelo de negocio consistente en seleccionar noticias previamente editadas y publicadas, las empresas de "press clipping" se están aprovechando del esfuerzo de los distintos editores de los diarios, de las inversiones en medios materiales y personales que los mismos realizan y fundamentalmente del trabajo diario de multitud de profesionales del periodismo volcados en información a la publicación de los hechos acaecidos en el día a día. ${ }^{15}$

\footnotetext{
${ }^{14}$ RiberA, Begoña, "Recopilaciones periódicas, reseñas, revistas de prensa y press clipping", en Juan Antonio Moreno Martínez (coord.), Limites a la propiedad intelectual y nuevas tecnologías, Madrid, Dickynson, 2009, p. 468. ${ }^{15}$ Peinado, Juan Ignacio y Solana, Diego, "Press Clipping: competencia desleal y propiedad intelectual", Estudios RCD, 2008 , p. 58.
} 
Marín ${ }^{16}$ también ha criticado la norma señalando que, teniendo en cuenta que el régimen de remuneración equitativa que establece la norma intenta subsanar los efectos de la actividad: "Desde la perspectiva de los intereses de los editores, hubiera sido sin duda preferible que el artículo 32.1 II LPI.E conservara la redacción que tenía antes". Afirma que sus modificaciones son una invitación a la masificación de estas prácticas. En materia de jurisprudencia en Europa, destacamos las siguientes sentencias:

El Tribunal Supremo Alemán, con fecha 17 de julio de 2003, resolvió el caso conocido como "Paperboy". En este caso, algunos editores periodísticos denunciaron al titular de la página web www.paperboy.de, la cual ofrecía el servicio de búsqueda de noticias, utilizando para ello enlaces profundos (deep linking). En la resolución, el Tribunal manifestó que la sola puesta a disposición de enlaces profundos no constituía una infracción al derecho de autor de los titulares de las páginas web enlazadas.

El Tribunal de Copenhague, por su parte, en 2002, resolvió el caso entre la Asociación de Editores de Dinamarca y la empresa Newsbooster. Esta última listaba una serie de enlaces profundos de noticias a través de su página web, www.newsbooster.com, con lo cual facilitaba a sus usuarios el acceso al texto íntegro de artículos periodísticos. En este caso, el Tribunal resolvió prohibir a la demandada el uso de dichos enlaces. ${ }^{17}$

En el caso Le Monde contra Microfor, la primera, importante cadena editorial periodística europea, demandó a la segunda por la realización de un índice de artículos de periódicos en Francia. Éste constaba de dos partes: sección analítica que permitía identificar los artículos a través de palabras clave, descriptores y fechas; y sección de resúmenes descriptivos de cada artículo, consistente en citas cortas. La acción dio lugar a cinco juicios, entre los años 1980 a 1987. Se llegó inclusive al Tribunal de Casación Francés. Según Kerever, ${ }^{18}$ en el fallo de 1987 del Tribunal de Casación se consagra la libertad de realizar un índice de los artículos periodísticos.

Sobre los títulos de los periódicos, el Tribunal de Casación indica que la edición del índice con fines documentales y la mención de los títulos para su identificación no es contrario al derecho exclusivo de explotación de la obra, sino que evita confundir la obra citante con la obra citada. Agrega el Tribunal

\footnotetext{
${ }^{16}$ MARin LóPEZ, JuAn José, "Derecho de autor, revistas de prensa y Press Clipping", Revue Internationale du Droit D'Auteur, vol. 215, p. 75.

${ }^{17}$ Córdova, Jorge, "El press clipping y el uso de enlances desde la perspectiva del derecho de autor", Revista de Derecho PucP, núm. 74.

${ }^{18}$ KenEVer, A., "Setencias Microfor", Reveu Internationale du Droit d'Auter, vol. 137.
} 
que este tipo de obras son una base de datos y, por ende, un tipo particular de recopilación. Así, su originalidad consta en la presentación del conjunto de las composiciones.

\section{La protección en Chile}

Como hemos dicho, la actividad de seguimiento y monitoreo de prensa se centra en artículos periodísticos. El artículo 3 de la Ley 17.336, de Propiedad Intelectual, recoge un listado no taxativo de obras protegidas. Entre ellas incluye en su numeral 6 "los periódicos, revistas u otras publicaciones de la misma naturaleza".

Este numeral, como ha indicado Walker, ${ }^{19}$ se refiere a "obras que utilizan el lenguaje como forma de expresión [protegiendo] en base a un criterio amplio [...] desde libros, guías y cualquier obra escrita con independencia de su naturaleza". Por lo tanto, pueden clasificarse la categoría de obras literarias y de carácter colectivas.

Estas obras son reguladas de manera detallada en la Ley 17.336. Se establece que, generalmente, radica en la empresa periodística la facultad de su publicación. En efecto, el artículo 24 letra c) de la ley desarrolla esta materia. Está centrada en quién tiene la autorización para realizar la publicación correspondiente y la titularidad sobre la obra resultante:

c) En diarios, revistas y otras publicaciones periódicas: 1) La empresa periodística adquiere el derecho de publicar en el diario, revista o periódico en que él o los autores presten sus servicios, los artículos, dibujos, fotografías y demás producciones aportadas por el personal sujeto a contrato de trabajo, reteniendo sus autores los demás derechos que ésta ley ampara. La publicación de esas producciones en otros diarios, revistas o periódicos de la misma empresa, distintos de aquél o aquéllos en que se presten los servicios, dará derecho a sus autores al pago adicional del horario que se señale el Arancel del Colegio de Periodista de Chile. Si la publicación se hace por una empresa periodística distinta de la empleadora, aquélla deberá pagar al autor o autores el honorario que establezca el mencionado Arancel. El derecho a las remuneraciones establecidas en el inciso anterior prescribe en el plazo de un año contado desde la respectiva publicación de las producciones; pero se suspende

\footnotetext{
${ }^{19}$ WALKER, ELISA, Manual de propiedad intelectual, Santiago, Thomson Reuters, 2014.
} 
en favor del autor o autores, respecto de la empresa periodística empleadora, mientras esté vigente el contrato de trabajo. 2) Tratándose de producciones encomendadas por un medio de difusión a personas no sujetas a contrato de trabajo, aquél tendrá el derecho exclusivo para su publicación en la primera edición que se efectúe después de la entrega, a menos que hubiere sido encargada expresamente para una edición posterior. Transcurrido el plazo correspondiente, el autor podrá disponer libremente de ellas.

Por otra parte, el artículo 10.1 del Convenio de Berna, del cual Chile forma parte, se reconoce a la cita en forma de revista o dosier de prensa como un límite al derecho de autor, como se analizó anteriormente.

En Chile, la excepción del derecho de cita se encuentra en la primera parte del artículo 71 B de la Ley 17.336, que señala: "Es lícita la inclusión en una obra, sin remunerar ni obtener autorización del titular, de fragmentos breves de obra protegida, que haya sido lícitamente divulgada, y su inclusión se realice a título de cita o con fin de crítica, ilustración, enseñanza e investigación, siempre que se mencione su fuente, título y autor".

De acuerdo con esta norma, un elemento esencial es que los fragmentos de una obra protegida, en este caso artículos periodísticos o dosieres de prensa, deben incluirse en otra "obra" y ser breves.

Otra de las alternativas por considerar es si el dosier de prensa o los artículos periodísticos entregados al usuario por la empresa prestadora del servicio de seguimiento están agrupados en una compilación. En este caso, el problema se centra en determinar si este producto está dotado de originalidad. Debe ser un producto más elaborado que la mera recolección de información para obtener protección como una compilación. Esto de acuerdo con lo establecido en el artículo 3 número 1 de la Ley 17.336: "Quedan especialmente protegidos con arreglo a la presente ley [...] las enciclopedias, guías, diccionarios, antologías y compilaciones de toda clase".

En este ámbito, el régimen legal nacional sobre compilaciones dispone en el artículo 24 a) que "el organizador, [es] quien está obligado a obtener el consentimiento de los titulares del derecho de las obras utilizadas y pagar la remuneración que por ellos se convenga, salvo que se consigne expresamente que tal autorización se concede a título gratuito". 
A criterio de Walker, ${ }^{20}$ estas creaciones "son protegidas por el derecho de autor, porque se entiende que el criterio de selección de la colección es lo que le da carácter de obra original". Lo anterior sin perjuicio de que el sujeto que organiza la compilación debe obtener las autorizaciones o cesión de los derechos patrimoniales para explotar las obras que se encuentran contenidas en la revista.

De acuerdo con Schuster, ${ }^{21}$ "el derecho de autor no presenta dificultades para proteger compilaciones siempre y cuando éstas reúnan dos condiciones: que se trate de compilaciones de obras y que la elección de dichas obras o su disposición en la compilación presente originalidad".

Como vemos, un aspecto relevante es el de la originalidad. Dicha cuestión no está definida expresamente ni en el Convenio de Berna, que como hemos dicho reconoce en el artículos 2.5 la protección a las compilaciones, ni en la legislación chilena, pese a que, como dice Walker, ${ }^{22}$ se hace mención a ella en varias oportunidades.

De acuerdo con Antequera, ${ }^{23}$ la forma de expresión de una obra puede ser de cualquier modo, pero es independiente el mérito artístico de la obra en sí y la originalidad apunta a su individualidad. Es decir, "el producto creativo, por su forma de expresión, ha de tener suficientes características propias para distinguirlo de cualquiera del mismo género [...] la originalidad se presume y quien la niega debe probarla”.

Para autores como Walker, ${ }^{24}$ en el formato digital adoptado por estos servicios, la originalidad en la selección o disposición del contenido es mucho más evidente. En la mayoría de las ocasiones, se envía un listado de enlaces en consideración de los intereses del cliente. Por lo tanto, podrían estar amparadas como una base de datos las obras que se encuentra protegida especialmente en el número 17 del artículo $3^{\circ}$ de la Ley 17.336: "las compilaciones de datos o de otros materiales, en forma legible por máquina o en otra forma, que por razones de la selección o disposición de sus contenidos, constituyen creaciones de carácter intelectual”.

182 Como vemos, la diferencia que hace la ley entre compilación y base de datos no es muy clara, pues una se remite a la otra poniendo el énfasis en la

\footnotetext{
${ }^{20}$ WALKER, ELISA, Manual de propiedad intelectual, Santiago, Thomson Reuters, 2014.

${ }^{21}$ Schuster, Santiago, "Bases de datos originales y no originales". [Consulta: 19 de junio, 2017]. Disponible en: http:// www.scdbeta.scd.cl/curso_prop_int/curso_1/Bases\%20de\%20datos\%20originales\%20y\%20no\%20originales.pdf

${ }^{22}$ WaLKER, ELISA, Manual de propiedad intelectual, Santiago, Thomson Reuters, 2014.

${ }^{23}$ Antequera, Ricardo, Estudios de derecho de autor y derechos afines, Madrid, Reus, 2007.

${ }^{24}$ WALKER, ELISA, Manual de propiedad intelectual, Santiago, Thomson Reuters, 2014.
} 
lectura por máquina del material. Walker ${ }^{25}$ sin embargo, argumenta que las bases de datos pueden agrupar material que usen lenguaje, pero a su vez pueden ser una selección de imágenes en movimiento o estáticas, sonidos u otros elementos que no corresponden a obras literarias, sino más bien se relacionan con las artísticas, musicales, entre otras. En cambio, las compilaciones consisten únicamente en obras literarias, total o parcialmente, agrupadas en una obra.

En cualquier caso, en todas las situaciones, compilaciones o bases datos, surge la interrogante sobre los vínculos y si éstos están protegidos por derechos de autor. Para Pabón, ${ }^{26}$ "como lo ha sostenido la doctrina y la jurisprudencia, los enlaces son una indicación de hechos (una dirección donde está ubicado un contenido) por lo que no tienen protección por el derecho de autor".

De acuerdo con lo anterior, sólo tienen protección los criterios de selección o determinación de la disposición del contenido de una base de datos de recortes de prensa, ya que ello permite dotar de originalidad a la obra. Con todo, cuando estos enlaces usan obras protegidas por derechos de autor, la situación se torna más problemática.

Recordemos que para Schuster ${ }^{27}$ las materias contenidas en la base de datos pueden ser no sólo obras literarias, artísticas o científicas, sino también materiales tales como "textos, sonidos, imágenes, cifras, hechos y datos". Por ello, la base de datos entregada al cliente puede contener la reproducción total, parcial o el uso de un fragmento de los artículos periodísticos, como otros elementos. Baste recordar que normalmente este servicio lo realizan los periodistas, documentalistas, e incluso especialistas en las áreas declaradas de interés del cliente. Ellos son quienes seleccionan y recopilan los artículos de prensa, por lo que inevitablemente hay un proceso intelectual de selección, disposición y descripción de los enlaces.

$\mathrm{Al}$ respecto, Schuster, ${ }^{28}$ refiriéndose al artículo 3.1 de la Directiva de la Comunidad Europa, indica que:

Los criterios, en virtud de los cuales las bases de datos son susceptibles de la protección por derecho de autor deben limitarse al hecho de que

\footnotetext{
${ }^{25}$ WaLKER, ElISA, Manual de propiedad intelectual, Santiago, Thomson Reuters, 2014.

${ }^{26}$ PABón, JHOnNy, "Hipertexto, links y derecho de autor", Porta de e-governo, inclusao digital e sociedade do conhecimento. [Consulta: 19 de junio, 2017]. Disponible en: http://www.egov.ufsc.br/portal/conteudo/hipertexto-links-y-derecho-de-autor

${ }^{27}$ Schuster, Santiago, "Bases de datos originales y no originales". [Consulta: 19 de junio, 2017]. Disponible en: http:// www.scdbeta.scd.cl/curso_prop_int/curso_1/Bases\%20de\%20datos\%20originales\%20y\%20no\%20originales.pdf ${ }^{28}$ Schuster, SAntiago, "Bases de datos originales y no originales", p. 8. [Consulta: 19 de junio, 2017]. Disponible en: http:// www.scdbeta.scd.cl/curso_prop_int/curso_1/Bases\%20de\%20datos\%20originales\%20y\%20no\%20originales.pdf
} 
la selección o disposición del contenido de la base de datos constituya una labor de creación propia del autor [...] no deb[en] aplicarse más criterios que la originalidad en el sentido de creación intelectual y, en especial, no se deben aplicar criterios estéticos o cualitativos.

De este modo, como señala Pabón, ${ }^{29}$ el conjunto de listados de enlaces, sean éstos únicamente vínculos, hipervínculos o fragmentos de artículos periodísticos o dosieres de prensa, junto a sus respectivos enlaces, son una creación intelectual protegida por derechos de autor si reúnen los requisitos descritos en el número 17 del artículo 3 de la Ley 17.336.

\section{Conclusiones}

Hecho el análisis a la luz de nuestra legislación, podemos concluir que no es posible al prestador del servicio de seguimiento o monitoreo de noticias amparar su proceso de recopilación bajo la excepción de derecho de cita contemplada en el artículo $71 \mathrm{~B}$ de la LPI. Lo anterior dado que un elemento determinante para configurarla es su inserción en "otra” obra, y que se trate de fragmentos breves. Dicha cuestión normalmente no ocurre en el caso, pues se reproduce completamente o fragmentos extensos de los artículos.

Por otro lado, sí sería posible obtener la protección bajo el concepto de compilación, obra protegida de acuerdo con lo establecido en el artículo 3 número 1 de la Ley 17.336. En dado caso, se debe probar la originalidad y pagar $\mathrm{u}$ obtener la renuncia a los derechos patrimoniales correspondientes por parte de los autores de los respectivos artículos compilados, conforme dispone el artículo 24.

Del mismo modo, puede proteger sus derechos alegando que se trata de una base de datos, obra protegida en el artículo 3 número 17 de la Ley 17.336.

\footnotetext{
${ }^{29}$ PABÓN, JHonny, "Hipertexto, links y derecho de autor", Porta de e-governo, inclusao digital e sociedade do conhecimento. [Consulta: 19 de junio, 2017]. Disponible en: http://www.egov.ufsc.br/portal/conteudo/hipertexto-links-y-derecho-de-autor
} 


\section{Referencias}

Antequera, Ricardo, Estudios de derecho de autor y derechos afines, Madrid, Reus, 2007.

Caparrós de Olmedo, Silvia, "El derecho de Cita y el Press Clipping”, en Nuria Ginés Cantellet (coord.), Novedades en la Ley de Propiedad Intelectual, Barcelona, Bosch, 2007.

Carbajo, Fernando, "El concepto de autor en el pseudolímite de recortes de prensa (Press Clipping)", Sentencia de la Audiencia Provincial de Madrid, sección 28, 2 de diciembre del 2011, en V. Jurisprudencia y Resoluciones.

“Code de la Propiété Intelectuelle”, Legifrance. [Consulta: 19 de junio, 2017]. Disponible en: https://www.legifrance.gouv.fr/affichCode.do;jsessionid=7CAOF3607D3FF0AAA125D75D1F19A44D.tpdila19v_3? cidTexte=LEGITEXT000006069414\&tdateTexte $=20170701$

“Código do Direito de Autor e dos Direitos Conexos”, Portal da Comunicaçao Social. [Consulta: 19 de junio, 2017]. Disponible en: http://www.gmcs.pt/pt/direito-de-autor-e-direitos-conexos

CóRDova, JoRge, "El press clipping y el uso de enlances desde la perspectiva del derecho de autor", Revista de Derecho PucP, núm. 74.

"Convenio de Berna para la Protección de Obras Literarias y Artísticas", Organización Mundial de la Propiedad Intelectual. [Consulta: 19 de junio, 2017]. Disponible en: http://www.wipo.int/treaties/es/text.jsp?file_id=283698\#P94_12427

“Directiva 2001/29/CE, de 22 de mayo de 2001, relativa a la armonización de determinados aspectos de los derechos de autor y derechos afines a los derechos de autor en la sociedad de la información”, Eur-lex. [Consulta: 19 de junio, 2017]. Disponible en: http://eur-lex.europa.eu/legal-content/ES/ALL/?uri=CELEX:32001L0029

Iglesias, RubÉn, "Provisión de enlaces electrónicos a contenidos protegidos por el derecho de autor", Actas de Derecho industrial y Derecho de Autor, núm. 32.

Kerever, A., "Setencias Microfor", Reveu Internationale du Droit d'Auter: (RIDA), vol. 137.

"Legge de 1941 Protezione del diritto d'autore e di altri diritti connessi al suo esercizio", Interlex. [Consulta: 19 de junio, 2017]. Disponible en: http://www. interlex.it/testi/141_633.htm

"Ley de Derecho de Autor y Derechos Conexos (Alemania)", Bundesministerium der Justiz und für Verbraucherschutz. [Consulta: 19 de junio, 2017]. Disponible en http://www.gesetze-im-internet.de/urhg

"Ley 17.336, sobre Propiedad Intelectual”, Ley Chile. [Consulta: 19 de junio, 2017]. Disponible en: http://www.leychile.cl/Navegar?idNorma=28933

Marín López, Juan José, “Derecho de autor, revistas de prensa y Press Clipping”, Revue Internationale du Droit D'Auteur, vol. 215. 
Ortega, JuAn Francisco, "Linking y derechos de autor: otro reto para equilibrio entre derechos exclusivos y excepciones. Una visión desde el derecho español”, Revista de Derecho, comunicaciones y nuevas tecnologias, núm. 5.

Pabón, Jhonny, "Hipertexto, links y derecho de autor", Porta de e-governo, inclusao digital e sociedade do conhecimento. [Consulta: 19 de junio, 2017]. Disponible en: http://www.egov.ufsc.br/portal/conteudo/hipertexto-links-y-derecho-de-autor

Peinado, Juan Ignacio y Solana, Diego, "Press Clipping: competencia desleal y propiedad intelectual”, Estudios RCD, 2008.

"Real Decreto Legislativo 1/1996, de 12 de abril, por el que se aprueba el texto refundido de la Ley de Propiedad Intelectual, regularizando, aclarando y armonizando las disposiciones legales vigentes sobre la materia”, Gobierno de España. [Consulta: 19 de junio, 2017]. Disponible en: https://www.boe.es/ buscar/act.php?id=BOE-A-1996-8930\&tn=1Etp=20141105

RIBERA, BEgoÑA, "Recopilaciones periódicas, reseñas, revistas de prensa y press clipping”, en Juan Antonio Moreno Martínez (coord.), Limites a la propiedad intelectual y nuevas tecnologías, Madrid, Dickynson, 2009.

Schuster, Santiago, "Bases de datos originales y no originales". [Consulta: 19 de junio, 2017]. Disponible en: http://www.scdbeta.scd.cl/curso_prop_int/curso_1/Bases\%20de\%20datos\%20originales\%20y\%20no\%20originales.pdf

Toвón, Natalia, Legalidad del "Press Clipping", Revista Foro Derecho Mercantil, núm. 47.

WaLKer, ElisA, Manual de propiedad intelectual, Santiago, Thomson Reuters, 2014. 